\title{
JAUNDICE AND INFANTILE DIARRHOEA
}

\author{
BY \\ R. G. F. PARKER \\ From the Bernhard Baron Institute, the London Hospital
}

(RECEIVED FOR PUBLICATION NOVEMBER 5, 1957)

Although it is recognized that infantile diarrhoea may sometimes be complicated by jaundice, the pathogenesis of this jaundice has not been fully elucidated. The only detailed account of the hepatic lesions in infantile diarrhoea is that of Wainwright (1950), who described in 11 of his 16 cases a form of 'hepatitis' characterized by periportal parenchymal necrosis, infiltration by polymorphonuclear leucocytes and mononuclear cells, proliferation of small bile ducts, inconstant fibrosis, periportal fatty change, distension of bile canaliculi in the centres of the lobules and congestion accompanied by varying degrees of centrilobular necrosis. In his remaining four cases there was centrilobular bile retention only. Wainwright noted a resemblance to experimental allyl formate poisoning and considered the hepatitis to be due to toxic parenchymal damage. Holland and O'Connor (1949) also attributed liver damage in infantile diarrhoea to hypothetical toxins, whilst Schlesinger, Payne and Burnard (1949) invoked nutritional deficiency.

The 13 cases which form the basis of this report came to necropsy in the Bernhard Baron Institute of the London Hospital in the years 1934 to 1954. They appear essentially similar to those described by Wainwright, although a different interpretation will be placed upon the pathogenesis of the hepatic lesions.

\section{Description of Cases}

In 9 of the 13 cases jaundice was noted during life or at necropsy. The remaining four cases were encountered unexpectedly when histological preparations were examined from 50 'control' cases of infantile diarrhoea without recorded jaundice which had come to necropsy in the years 1929 to 1956. Since in the same period there were many necropsies upon similar cases in which the liver was not examined microscopically, the true incidence of the lesions to be described could not be assessed. The hepatic lesions in the four cases without recorded jaundice were essentially similar, both qualitatively and quantitatively, to those found in cases with overt jaundice. The main features of all 13 cases are summarized in the Table.

Aetiology. The stools were examined bacteriologically in eight cases, no pathogenic organisms being found. In only the most recent case however was special search made for pathogenic strains of Esch. coli. The possibility of infection from a single source or of cross infection arose only in Cases 1, 2 and 8, all three of whom were in the same ward of the hospital at the same time. Two of these (Cases 1 and 8) developed both diarrhoea and jaundice whilst in hospital, having been admitted for other conditions. Case 2 was admitted with diarrhoea, jaundice appearing later. At this time there was in the same ward a child of 5 years with clinically typical virus hepatitis.

Clinical Features. It has already been noted that in four cases jaundice was not recorded during life or at necropsy. In a fifth it was present at necropsy although there was no mention of it in the clinical notes. In these five cases the duration of diarrhoea was from eight to 22 days, and in the remaining cases it was from nine to 28 days. In all but one of this latter group diarrhoea preceded jaundice by a period of seven to 16 days. In Case 12 there was vomiting for two days before jaundice was noted, but diarrhoea did not commence for another 10 days. The duration of jaundice was short (one to four days) in five cases. In the remaining three it was nine, 18 and 37 days respectively. It is clear however, from the presence of hepatic lesions without recorded jaundice and from lack of correlation between the duration of jaundice and the apparent age of the lesions as judged histologically (see Table), that jaundice was an unreliable indication of hepatic involvement in this series. The available clinical and laboratory data gave no clear indication of the nature of the jaundice, although an obstructive element was suggested in some cases. Death was not definitely attributable to hepatic failure in any case. 
TABLE

CLINICAL AND PATHOLOGICAL FINDINGS IN 13 CASES OF INFANTILE DIARRHOEA WITH JAUNDICE

\begin{tabular}{|c|c|c|c|c|c|c|c|c|c|}
\hline $\begin{array}{l}\text { Case } \\
\text { No. }\end{array}$ & $\begin{array}{c}\text { Sex, } \\
\text { Age } \\
\text { (mths.) }\end{array}$ & $\begin{array}{c}\text { Duration } \\
\text { Diarrhoea }\end{array}$ & $\begin{array}{l}\text { (Days) of } \\
\text { Jaundice }\end{array}$ & $\begin{array}{l}\text { Bile } \\
\text { Thrombi }\end{array}$ & $\begin{array}{c}\text { Proliferation } \\
\text { of } \\
\text { Bile Ducts }\end{array}$ & $\begin{array}{c}\text { Infiltrate } \\
\text { in } \\
\text { Portal Tracts }\end{array}$ & Fibrosis & $\begin{array}{l}\text { Fatty } \\
\text { Change }\end{array}$ & Siderosis \\
\hline 1 & F 5 & 9 & 2 & Scanty & Slight & $\begin{array}{c}\text { Scanty } \\
\text { polymorphs }\end{array}$ & Absent & Marked & Slight \\
\hline 2 & F 5 & 13 & 4 & Scanty & Moderate & $\begin{array}{l}\text { polymorpns } \\
\text { Many }\end{array}$ & Slight & Marked & Absent \\
\hline 3 & M 5 & 17 & 1 & Scanty & Marked & Moderate & Slight & Very & Absent \\
\hline 4 & M $2 \frac{1}{2}$ & 8 & Absent & Many & Slight & $\begin{array}{l}\text { polymorphs } \\
\text { Slight } \\
\text { polymorphs }\end{array}$ & Absent & $\begin{array}{c}\text { marked } \\
\text { Slight }\end{array}$ & Slight \\
\hline 5 & M 41 & 17 & Absent & Scanty & Slight & $\begin{array}{l}\text { Scanty } \\
\text { polymorphs }\end{array}$ & Absent & Marked & Absent \\
\hline 6 & M 8 & 13 & Absent & Moderate & Moderate & $\begin{array}{l}\text { Moderate polymorphs } \\
\text { and lymphocytes }\end{array}$ & Slight & Marked & Absent \\
\hline 7 & 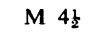 & 10 & P.M. only & Many & Moderate & $\begin{array}{c}\text { Moderate polymorphs } \\
\text { and lymphocytes }\end{array}$ & Slight & Moderate & Absent \\
\hline 8 & F 8 & 28 & 18 & Moderate & $\begin{array}{l}\text { Probably } \\
\text { slight }\end{array}$ & $\begin{array}{l}\text { Scanty } \\
\text { mononuclears }\end{array}$ & Moderate & Slight & \\
\hline 9 & F 2 & 9 & 2 & Many & Slight & $\begin{array}{c}\text { Scanty } \\
\text { mononuclears }\end{array}$ & Moderate & Slight & Moderate \\
\hline 10 & F 21: & 19 & 9 & Moderate & Doubtful & $\begin{array}{l}\text { Scanty } \\
\text { mononuclears }\end{array}$ & Marked & Moderate & Slight \\
\hline 11 & M 4 & 13 & 1 & Many & Slight & Absent & Slight & Absent & Moderate \\
\hline 12 & F 21 & 27 & 37 & Many & Absent & Absent & Absent & Absent & Marked \\
\hline 13 & F 9 & 22 & Absent & Moderate & Absent & Absent & Absent & Absent & Slight \\
\hline
\end{tabular}

Pathology. Focal ulceration of the gastrointestinal tract was noted at necropsy in one case only. Histologically the stomach and intestines in the remainder showed only a mild or moderate nonspecific acute inflammatory process, sometimes with marked oedema. Changes in organs other than the alimentary tract and liver were incidental or unimportant.

The hepatic lesions could be divided histologically into those (Cases 1 to 10, hereafter called Group I) in which there was, in addition to bile retention within the lobules, evidence of an inflammatory process in and around the portal tracts; and those (Cases 11 to 13, Group II) in which the appearances were those of obstructive jaundice without evidence of infection. This division (which is similar to that made by Wainwright, 1950) may not however be an absolute one, for, as the Table shows, there were borderline lesions (particularly in Case 4) in which biliary obstruction was marked and portal inflammation only slight.

Group I. In all 10 cases distended bile canaliculi at the centres of the lobules suggested obstruction to the flow of bile, slight in Cases $1,2,3$ and 5, moderate or well-marked in the remainder (Fig. 1). In the first seven cases there was a polymorphonuclear leucocytic infiltration of the portal tracts, some of these cells being within the lumina of small bile ducts but the majority lying in the portal connective tissue or at the extreme periphery of the lobules (Fig. 2). A slight degree of periportal fibrosis was present in Cases 2 and 3 and also in Cases 6 and 7, where the presence of lymphocytes as well as polymorphonuclear leucocytes provided additional evidence of a relatively subacute inflammatory process. In Cases 8, 9 and 10 fibrosis was more pronounced, the inflammatory cell infiltrate was mild and polymorphonuclear leucocytes were virtually absent. Proliferation of small bile ducts was seen in all the more acute cases (Figs. 2 and 3), mitotic figures being usually present. Where periportal fibrosis was at all marked however it was difficult to distinguish such newly formed ducts from parenchymal trabeculae caught up in the fibrous tissue. Fatty change was present in all 10 cases, although in very varying degree. Except in the liver with most fat (Case 3) it was essentially periportal in distribution. There were no necrotic cells still in situ in the first nine cases. It was apparent however that, as a result of periportal inflammation, some cells had been lost from the extreme periphery of the lobules, and the presence of parenchymal mitotic figures in three cases was additional evidence of this. In Case 10 there was marked sinusoidal congestion at the centres of the lobules, and there appeared to be some loss of parenchymal cells associated with this. There was however no condensation of reticulin in the central zones, and it is probable that much of the apparent cell loss was a post-mortem artefact. Finally, slight to moderate haemosiderosis was found in five of the 10 cases, both parenchymal cells and reticulo-endothelial cells containing pigment.

Group II. In Cases 11, 12 and 13 inflammatory changes were absent and the most striking abnormality in the liver was moderate or pronounced 


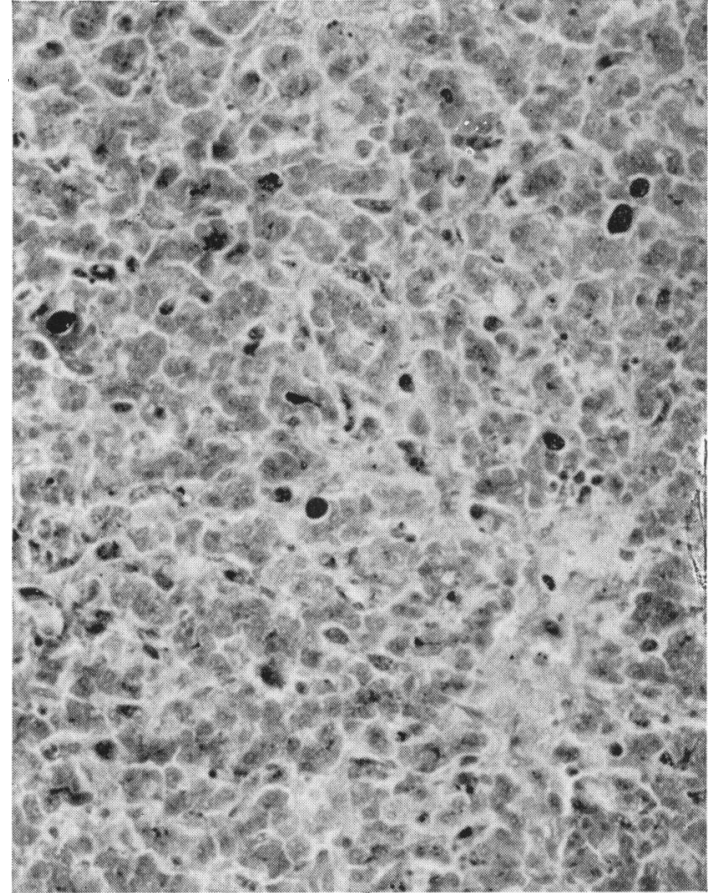

Fig. 1.-Case 4. A central vein is shown near bottom right-hand corner. There are several darkly stained bile thrombi. the majority

in the centrilobular region. Haematoxylin and eosin. $\times 185$.

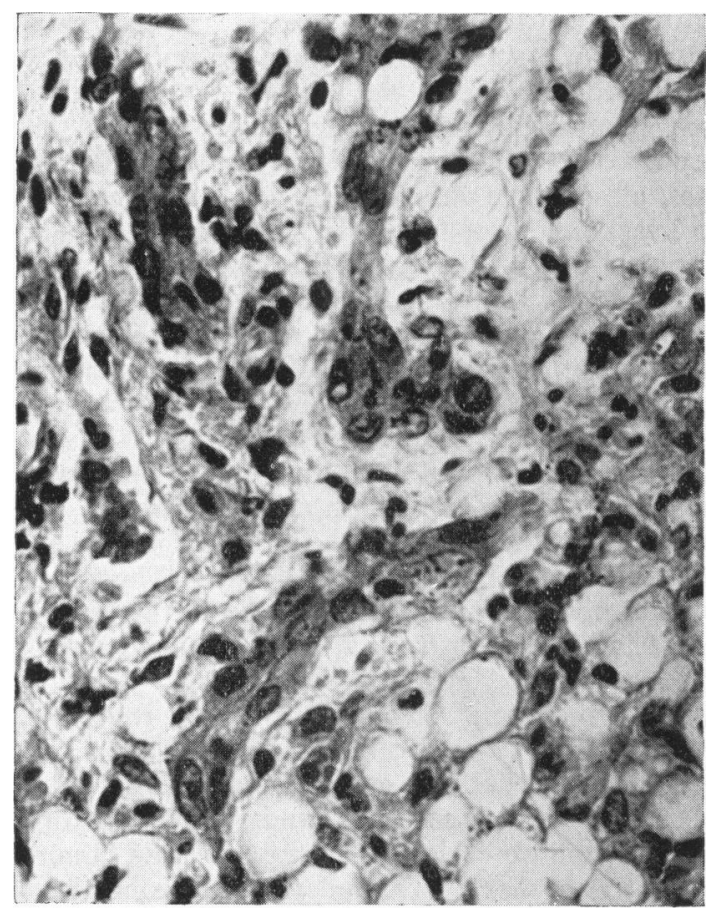

FIG. 2.-Case 2. Periportal fatty change proliferation of small bile ducts and infiltration by polymorphonuclear neutrophils. Haematoxylin and eosin. $\times 490$

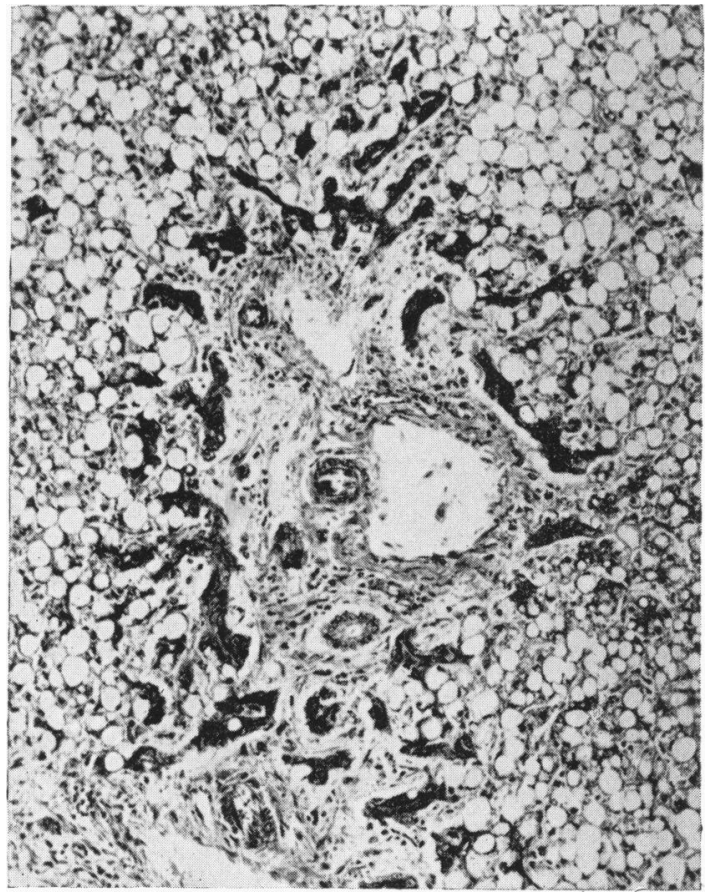

D

Fig. 3.-Case 6. Proliferation of small bile ducts around a portal tract and severe fatty change. Phosphotungstic acid-haematoxylin. $\times 120$.

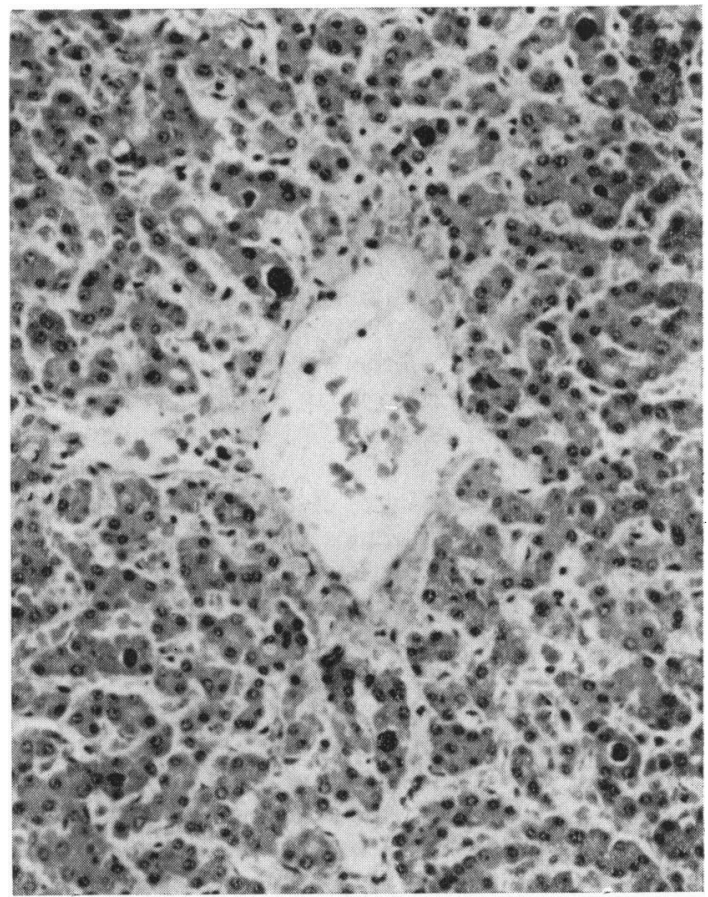

FIG. 4.-Case 11. Bile thrombi in central zone of lobule. Periodic acid-Schiff. $\times 185$.
을. 
intralobular bile retention (Fig. 4). In Case 11 there was also slight proliferation of small bile ducts such as occurs in obstructive jaundice without accompanying inflammation, and the very slight degree of periportal fibrosis was no more than might be expected to accompany such bile duct proliferation. In Case 12 a few eosinophilic necrotic cells were present, but the appearances did not otherwise suggest virus hepatitis. Haemosiderosis was present in all three cases and occasional focal parenchymal necroses in the third.

\section{Discussion}

The pathogenesis of the hepatic lesions in these cases must be inferred very largely from the histological findings. Certain deductions of negative value may first be made. Thus although three cases (Cases 8, 9 and 11) had received blood transfusions, the microscopical features (many bile thrombi in all three, moderate periportal fibrosis in two and bile duct proliferation in the third) could hardly be attributed to haemolysis. Next, the only resemblance to neonatal hepatitis as described by Dible, Hunt, Pugh, Steingold and Wood (1954) was the presence of haemosiderosis in seven cases. A similar degree of iron pigmentation was noted in several cases of infantile diarrhoea without the hepatic lesions described above, and it was considered therefore to be a relatively non-specific finding. Nor was the picture that of virus hepatitis as seen in older subjects, the infiltration by polymorphonuclear leucocytes being particularly against this diagnosis.

Wainwright (1950) considered the essential hepatic lesion in most of his cases to be periportal parenchymal necrosis, the other changes being secondary. In all the lesions described here periportal necrosis was minimal, being readily accounted for by the inflammatory process in and around the portal tracts. It was this portal and periportal inflammation which, together perhaps with extrahepatic biliary obstruction, appeared to be the essential hepatic abnormality in the first 10 cases in this series. Localization of the inflammation to the portal tracts might have been due to haematogenous infection, but the available evidence favoured rather an initial infection of the biliary tract, an ascending cholangitis. Thus inflammatory cells were sometimes present within the lumina of the smallest bile ducts and these same ducts showed unequivocal evidence of proliferation. Bile retention was usually in excess of what might have been expected from the amount of parenchymal damage present, and was therefore probably the result of biliary obstruction. The inflammation in and around the portal tracts probably contributed to this obstruction, but poor correlation between the intensity of the inflammation and of the bile retention suggested that the larger bile ducts may sometimes have been partly occluded. Extra-hepatic biliary obstruction was not found at necropsy in any case in this series or in that of Wainwright, and this author, whilst noting the resemblance of his lesions to cholangitis, considered the absence of demonstrable obstruction to be clear evidence that this was not their true nature. There are two objections to this conclusion. First it is doubtful whether the routine examination of the bile ducts performed at necropsy is adequate to exclude obstruction due to inflammatory swelling in the infant especially when, as the clinical evidence usually suggested in this series, the obstruction is incomplete. Secondly, whilst ascending cholangitis is very frequently associated with obstruction in adults, it would be wrong to assume that it cannot occur in the absence of obstruction in infants. Absence of inflammation in the extra-hepatic ducts would be important evidence against a non-obstructive ascending cholangitis. Wainwright failed to find such inflammation, but it is not clear how often the large bile ducts were examined in his cases. Unfortunately no sections of the extra-hepatic ducts were taken in the present series. In one section of the gallbladder (Case 9) there was definite evidence of mild inflammation.

It is considered therefore that the hepatic lesion in the first 10 cases of this series was essentially a cholangitis associated with bile retention which may have been due in part to inflammatory obstruction of the extra-hepatic bile ducts, a true catarrhal jaundice in fact. Case 4 , in which bile thrombi were numerous and inflammatory infiltration was slight, possibly bridged the gap between this group and the remaining three cases in the series (Group II) in which there was obstruction without evidence of intra-hepatic infection. Perhaps in these three cases the cholangitis had failed to reach the intrahepatic ducts. On the other hand Case 12 was unusual clinically in that jaundice preceded the diarrhoea, and it may be therefore that a different pathological process was in operation. Virus hepatitis could not be ruled out with certainty in this case.

No pathogenic organisms were isolated in these cases and the nature of the infecting agent remained obscure. Despite a history of contact with virus hepatitis in three cases the histological evidence favoured a bacterial rather than a viral infection. On epidemiological grounds it seemed possible that at least two of these same three cases had been 
infected from a single source. But it would be wrong to assume from this that there exist distinct icterogenic strains among the causative organisms of infantile diarrhoea. Cholangitis is not so uncommon a complication of this condition that it would be highly unlikely to occur in three successive cases by chance. Further bacteriological and epidemiological evidence is necessary to settle this point.

\section{Summary}

Nine fatal cases of infantile diarrhoea with jaundice and four cases without recorded jaundice but with identical hepatic lesions are described.

In 10 of these cases evidence of bile retention was associated with an inflammatory process in the portal tracts which was considered to be a cholangitis. In the remaining three cases there was bile retention without inflammation.

It is suggested that all cases may represent an ascending infection of the bile ducts, sometimes stopping short of the smallest ducts and associated with varying degrees of biliary obstruction. A bacterial rather than a viral infection is favoured but the causative organism was not identified.

I wish to thank Professor D. S. Russell for her helpful criticism and Dr. K. H. Tallerman and Dr. R. H. Dobbs for permission to include cases under their care.

\section{REFERENCES}

Dible, J. H., Hunt, W. E., Pugh, V. W., Steingold, L. and Wood, J. H.'F. (1954). J. Path. Bact., 67, 195

Holland, P. D. J. and O'Connor, M. H. (1949). Irish J. med. Sci. p. 261.

Schlesinger, B., Payne, W. W. and Burnard, E. D. (1949). Arch. Dis. Childh 24, 15 .

Wainwright, J. (1950). Ibid., 25, 286. 